\title{
Comparing relative abundance, lengths, and habitat of temperate reef fishes using simultaneous underwater visual census, video, and trap sampling
}

\author{
Nathan M. Bacheler ${ }^{1, *}$, Nathan R. Geraldi ${ }^{2}$, Michael L. Burton ${ }^{1}$, Roldan C. Muñoz ${ }^{1}$, \\ G. Todd Kellison ${ }^{1}$
}

${ }^{1}$ Southeast Fisheries Science Center, National Marine Fisheries Service, Beaufort, North Carolina 28516, USA

${ }^{2}$ Red Sea Research Center, King Abdullah University of Science and Technology, Thuwal 23955-6900, Kingdom of Saudi Arabia

\begin{abstract}
Unbiased counts of individuals or species are often impossible given the prevalence of cryptic or mobile species. We used 77 simultaneous multi-gear deployments to make inferences about relative abundance, diversity, length composition, and habitat of the reef fish community along the southeastern US Atlantic coast. In total, 117 taxa were observed by underwater visual census (UVC), stationary video, and chevron fish traps, with more taxa being observed by UVC (100) than video (82) or traps (20). Frequency of occurrence of focal species was similar among all sampling approaches for tomtate Haemulon aurolineatum and black sea bass Centropristis striata, higher for UVC and video compared to traps for red snapper Lutjanus campechanus, vermilion snapper Rhomboplites aurorubens, and gray triggerfish Balistes capriscus, and higher for UVC compared to video or traps for gray snapper L. griseus and lionfish Pterois spp. For 6 of 7 focal species, correlations of relative abundance among gears were strongest between UVC and video, but there was substantial variability among species. The number of recorded species between UVC and video was correlated $(\rho=0.59)$, but relationships between traps and the other 2 methods were weaker. Lengths of fish visually estimated by UVC were similar to lengths of fish caught in traps, as were habitat characterizations from UVC and video. No gear provided a complete census for any species in our study, suggesting that analytical methods accounting for imperfect detection are necessary to make unbiased inferences about fish abundance.
\end{abstract}

KEY WORDS: Survey $\cdot$ Detection $\cdot$ Baited remote underwater video station $\cdot$ CPUE $\cdot$ Centropristis striata $\cdot$ Lutjanus campechanus $\cdot$ Sampling gears $\cdot$ Reefs $\cdot$ Fisheries management

\section{INTRODUCTION}

Counting organisms is a basic and central component of ecology, management, and conservation. For instance, the conservation of endangered species, fisheries stock assessment, pest management, and predator control all rely on accurate population size or density estimates to be successful (Zuur et al. 2007). However, counting organisms can be ex-

*Corresponding author: nate.bacheler@noaa.gov tremely challenging because they often occur over large areas, can move, and may be cryptic, resulting in some or most individuals being missed by observers or sampling gears (MacKenzie et al. 2002, Elphick 2008). Therefore, unbiased population size estimates are rarely available, so researchers commonly make inferences about total population size or abundance across space and time by sampling the population of interest (Williams et al. 2002). Similarly, esti-

(C) N. R. Geraldi and outside the USA ( $)$ The US Government 2017. Open Access under Creative Commons by Attribution Licence. Use, distribution and reproduction are unrestricted. Authors and original publication must be credited.

Publisher: Inter-Research · www.int-res.com 
mating the total number of species is often useful information for management or conservation purposes, but biodiversity studies will be biased if they fail to detect species that are truly present at a site (Monk 2014, Klibansky et al. in press).

Elucidating trends in abundance over time and space is particularly challenging for the sustainable management of marine fishes. For marine fishes, total population abundance is typically estimated within a stock assessment model, which often relies upon external measures of relative abundance (i.e. indices of abundance) from survey or fishery-dependent data (Maunder \& Punt 2004). Although catch rates from surveys or fishermen are often assumed to be linearly related to true abundance, there are many examples where the rate of fish catch was nonlinearly related or unrelated to true abundance (Richards \& Schnute 1986, Harley et al. 2001). In lieu of information on absolute abundance and given the increasing awareness of the biases of various sampling gears, there has been a recent focus on comparing catches from multiple sampling gears (e.g. Willis et al. 2000, Cappo et al. 2004, Langlois et al. 2010, Karnauskas \& Babcock 2012, Parker et al. 2016). These studies help us understand what counts or catches can tell us about overall abundance (Yoccoz et al. 2001) and patterns in biodiversity (Collen et al. 2013).

Previous gear comparison studies have shown that catches for some gear and species combinations were correlated, while others were not (Ellis \& DeMartini 1995, Willis et al. 2000, Karnauskas \& Babcock 2012, Parker et al. 2016). For instance, Karnauskas \& Babcock (2012) showed that underwater visual census (UVC) and hook-and-line approaches were often correlated when collected at the same time and place for reef fishes, but correlations deteriorated when separated in space or time. Parker et al. (2016) found that stationary baited video cameras and hook-andline generally detected the same trends in fish abundance, but video had higher power to detect trends, suggesting it was the preferable gear. Similar results were found for video and longline sampling of juvenile pink snapper Pristipomoides filamentosus in Hawaii (Ellis \& DeMartini 1995), where gear-specific counts and catches were correlated but video had higher power. In contrast, Willis et al. (2000) indicated that UVC under-represented snapper Pagrus auratus abundance compared to video and hookand-line sampling, possibly due to a strong flight response of the heavily exploited snappers to divers.

All sampling gears are selective, disproportionately capturing certain sizes or species more than others, making it challenging to quantify the true abundance of fish across a landscape unless gear comparison studies are undertaken. For instance, baited capture gears such as hook-and-line, longlines, and traps tend to capture more predators and scavengers than expected based on their abundance (Murphy \& Jenkins 2010), and typically record fewer species than visual methods like UVC and video (Harvey et al. 2012, Bacheler et al. 2013a, Parker et al. 2016). The highest numbers of species tend to be recorded by UVC, but UVC tends to select against wary, highly mobile species and select for species that are highly visible and attracted to divers (MacNeil et al. 2008, Bozec et al. 2011, Mallet et al. 2014). Video sampling can also document many species, sometimes more than UVC (Langlois et al. 2010), and often fish counts from video vary in proportion to their true abundance (Willis et al. 2000, Schobernd et al. 2014, Parker et al. 2016). Video sampling can be influenced by water clarity and current direction (Bacheler et al. 2014). Sampling gears can also select for particular sizes of fish over others, with sizes of fish from hook-and-line or traps often being larger than fish seen with video or UVC (Willis et al. 2000, Harvey et al. 2012, Langlois et al. 2012, 2015, Parker et al. 2016). Given the relative dearth but critical importance of gear comparison studies like those described above, more studies are clearly needed to provide a comprehensive understanding of the biases of various sampling methods.

In this study, we compared UVC, video, and trap methods for indexing the abundance, length, and habitat of various reef fish species in the southeastern USA. Our approach was unique in that all 3 methods were applied simultaneously at a variety of sampling locations, allowing us to test for differences among gears after eliminating the influence of variability in reef fish abundance over space and time. Our first objective was to test for correlations in reef fish counts or catch among the 3 sampling gears, and we hypothesized that site-specific relative abundance from UVC and video would be more highly correlated with each other than either gear would be with traps. Second, we compared lengths of fish caught in traps to lengths estimated by UVC, hypothesizing that the lengths of fish caught in traps would be larger than from UVC. Last, we compared habitat observed on video with the habitat recorded by UVC, hypothesizing that habitat would be similar between video and UVC. The results will help to elucidate the strengths, weaknesses, and biases of 3 commonly used sampling methods, which will help us to understand how, or under what conditions, catches or counts are related to true abundance. 


\section{MATERIALS AND METHODS}

\section{Study area}

Our study was conducted at a number of hardbottom temperate reef sites on the continental shelf of the east coast of Florida, USA (Fig. 1). The continental shelf along the southeastern US Atlantic coast (hereafter 'SEUS') primarily consists of sand and mud substrates, but patches of hard, rocky, temperate reefs are scattered throughout the region and are important habitat for a variety of reef fish species. Specific hardbottom locations were chosen from the sampling frame of the Southeast Reef Fish Survey (Bacheler et al. 2014) using 2 criteria: safe diving depths $(<32 \mathrm{~m})$ and a history of reef fish being caught in traps. Hardbottom habitats sampled in our study ranged from patchily distributed pavement and rock

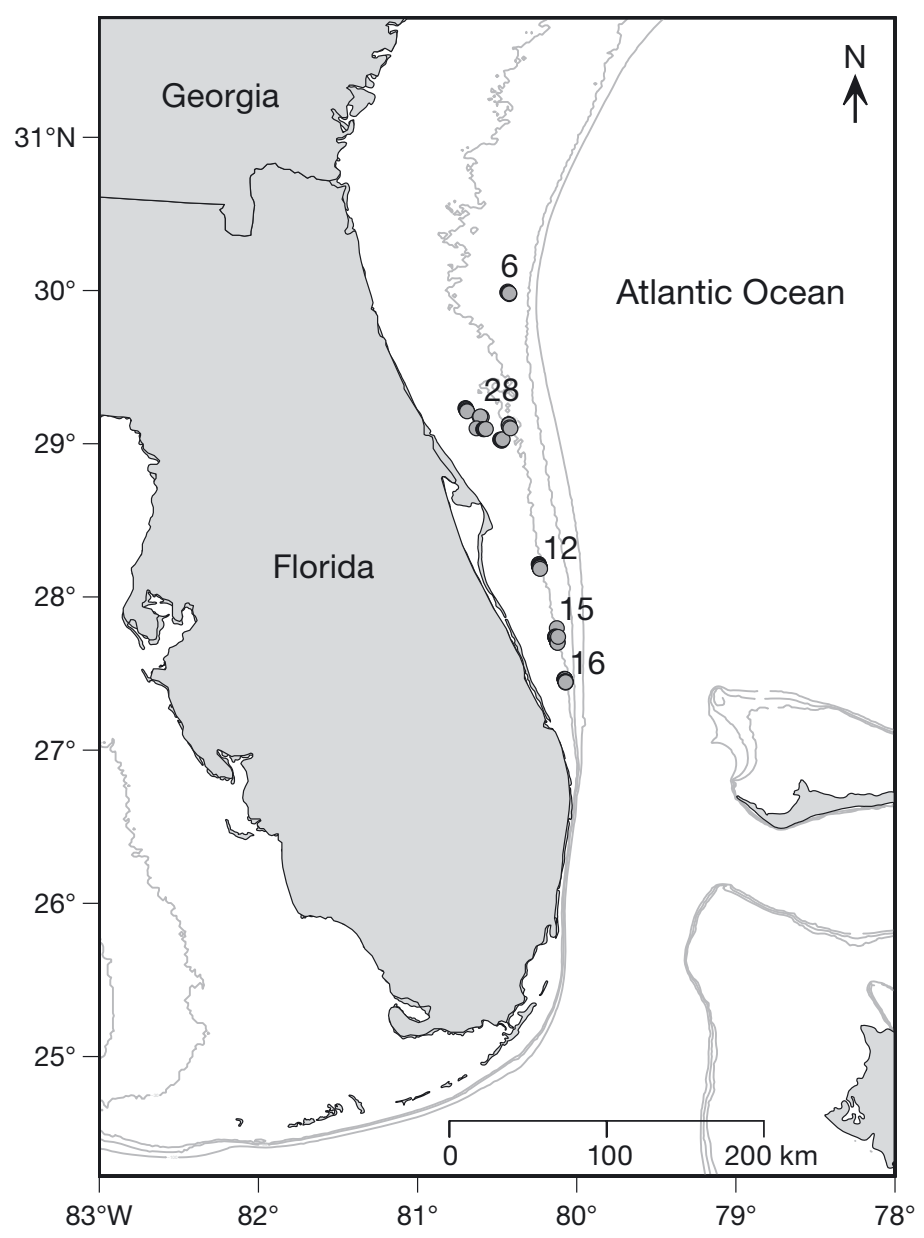

Fig. 1. Study area showing the location of simultaneous multi-gear sampling in Florida waters along the US east coast. Note that symbols showing sampling locations often overlap, so the number of stations in each cluster is provided. Gray lines indicate 30, 50, and $100 \mathrm{~m}$ isobaths outcrops, sometimes covered in a sand veneer, to rocky ledges. All sampling occurred between 18 and 30 m deep on 2-7 July 2014 aboard the MV 'Spree.'

\section{Chevron trapping}

Chevron traps were deployed at each station sampled in this study. Fish traps are a common reef fish sampling gear because they can fish unattended, can be deployed in a variety of different habitat types, are relatively inexpensive and robust, and typically catch fish alive, allowing for the release of bycatch (Miller 1990) or retention of fish for biological samples. Moreover, chevron fish traps have been used in the SEUS to index the abundance of a variety of reef fish species (e.g. Bacheler et al. 2013b), and catches of at least 1 reef species (black sea bass) have been shown to correlate well with true abundance (Bacheler et al. 2013c, Shertzer et al. 2016).

In this study, chevron traps were shaped like an arrowhead and measured $1.7 \times 1.5 \times 0.6 \mathrm{~m}$, with a volume of approximately $0.91 \mathrm{~m}^{3}$ (Collins 1990, Bacheler et al. 2014). The mouth of each trap was shaped like an upside down teardrop and measured approximately $45 \mathrm{~cm}$ high and $18 \mathrm{~cm}$ wide, and the mesh size of each trap was $3.4 \times 3.4 \mathrm{~cm}$. Traps were baited with approximately $4 \mathrm{~kg}$ of Brevoortia spp. A soak time of 90 min was targeted for each trap, but actual soak time varied from 51 to 99 min (mean \pm SE $=80 \pm 1.2 \mathrm{~min}$ ); Bacheler et al. (2013b) found no influence of soak time on chevron trap catches of most species examined between 50 and $150 \mathrm{~min}$. Each trap had a single $8 \mathrm{~mm}$ polypropylene line connecting it to 2 surface floats. Chevron traps were never deployed within $200 \mathrm{~m}$ of any other trap (usually $>400 \mathrm{~m}$ ) in this study to provide some measure of independence between traps. The response variable for trap catch was fish caught per trap, as recommended by Bacheler et al. (2013b). All fish caught in traps were measured to the nearest $\mathrm{mm}$ total length (TL).

\section{Underwater video}

Each chevron trap deployed in this study was outfitted with 2 outward looking video cameras (Fig. 2). A high-definition Canon ${ }^{\circledR}$ Vixia HF-S200 video camera with a factory-issued lens in a Gates underwater housing was attached over the mouth of each trap, facing away from the trap. A second high-definition video camera (GoPro ${ }^{\circledR}$ Hero HD) was attached over 


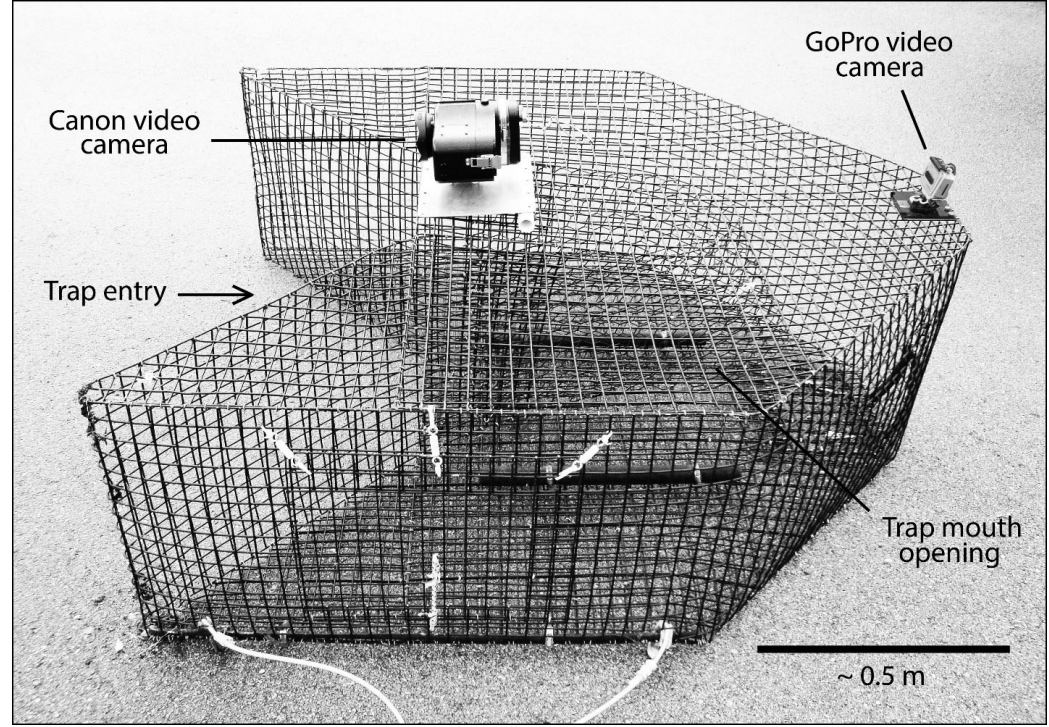

Fig. 2. Chevron trap with 2 attached underwater video cameras used during simultaneous multi-gear sampling along the east coast of Florida. Canon ${ }^{\circledR}$ Vixia HF-S200 and GoPro ${ }^{\circledR}$ Hero HD cameras faced outward from each end of the trap and both were used for counting fish and describing habitat

trap were summed to estimate relative abundance for each species at a site.

Some species groupings were challenging to differentiate by UVC and video due to subtle differences in anatomy or color. In these few instances, taxa were only identified to genus (e.g. Calamus spp., Decapterus spp., Paralichthys spp.).

Two habitat variables were quantified from each of the 2 video cameras attached to traps following the procedure described by Bacheler et al. (2014). Briefly, percent hard bottom was visually estimated as the percent of the observable substrate that consisted of hard, consolidated sediment at least $10 \mathrm{~cm}$ in diameter. Percent biotic coverage was visually estimated as the percent of the observable substrate covered by attached biota such as algae, sponges, or soft corals. For each habitat variable, the

the nose of each trap (the opposite direction of the Canon camera), also looking outward (Fig. 2). Both cameras were used to quantify fish and microhabitat features at each site.

We used a version of the MeanCount video metric described by Schobernd et al. (2014) to estimate the relative abundance of all reef fish species on each Canon video. MeanCount is calculated as the mean number of individuals of each species on a series of video frames in the video sample. The most commonly used video metric is $\operatorname{Max} N$, which is the maximum number of individuals of a single species observed in a single frame of a video clip. Schobernd et al. (2014) showed that MaxN reaches an asymptote at higher levels of true abundance, whereas MeanCount tracks true abundance linearly. The downside of MeanCount is that it may not detect all species known to be present at a site (Bacheler \& Shertzer 2015). Here, we used the MeanCount approach and read snapshots spaced every $30 \mathrm{~s}$ over a 20 min interval, beginning 10 min after the trap landed on the bottom, for a total of 41 snapshots. We used a slightly different derivation of MeanCount called SumCount (i.e. the sum of all individuals seen across the 41 frames), because it is measured in whole numbers. Note that SumCount is exactly linearly related to MeanCount when the number of frames read across all samples is the same (Bacheler \& Carmichael 2014); in our study, 41 snapshots were read for every sample. SumCounts from each of the 2 cameras on a mean of the 2 values ( 1 for each camera) was used as the video-based estimate for that site. These habitat variables were estimated for each video in our study by the same video reader using video as the trap landed on the bottom, while it was resting on the bottom, and while it was being retrieved.

\section{UVC}

Within 10 min of each trap (outfitted with video cameras) being deployed, 2 divers descended the trap line until the trap was visible. Staying at least $10 \mathrm{~m}$ from the trap, divers counted fish and measured habitat features along 3 transects that were each $30 \mathrm{~m}$ long and $10 \mathrm{~m}$ wide (i.e. $300 \mathrm{~m}^{2}$ surveyed for each transect and $900 \mathrm{~m}^{2}$ surveyed at each site). The first transect direction was typically chosen in the direction with the most hard bottom, usually beginning approximately $15 \mathrm{~m}$ from the trap, so as to disturb the trap and video sampling as little as possible (Fig. 3). The second transect occurred in the opposite direction of the first transect, and the third transect was perpendicular to the first 2 transects (Fig. 3) and often contained the least hardbottom habitat. The depths of habitats sampled by UVC were similar (within $2 \mathrm{~m}$ ) among transects and similar in all cases to the depth of trap and video sampling.

For each pair of divers, the first diver was responsible for counting fish and the other (trailing) diver was 


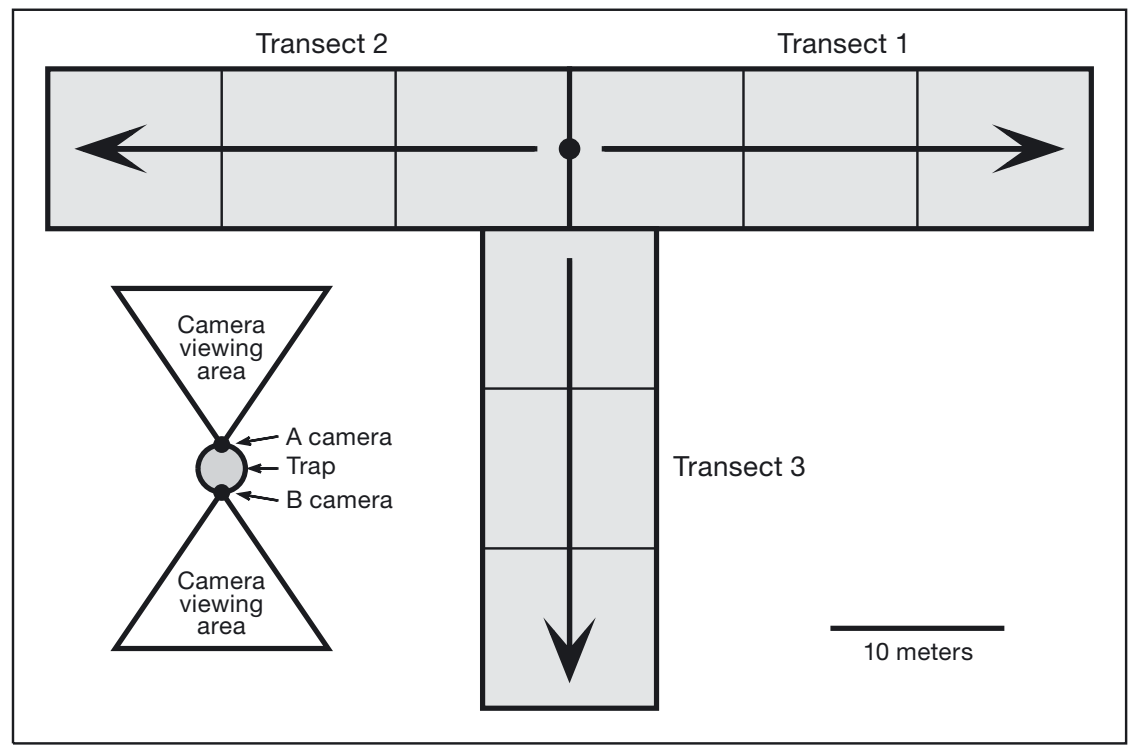

Fig. 3. Design for simultaneous underwater visual census (UVC), video, and trap sampling in Florida, 2014. Gray shading denotes areas over which UVC density estimates of reef fish species were obtained (each transect $=10$ $\times 30 \mathrm{~m}=300 \mathrm{~m}^{2}$ ), inner boxes indicate areas over which habitat was estimated during UVC surveys (mean of the 9 boxes was used in analyses), and arrows indicate direction of fish surveys. Cameras were attached to chevron fish traps and viewed areas away from the trap itself, indicated by the camera viewing area triangles (sizes are approximate). Note that the relative location and orientation of the trap and video cameras compared to the UVC transects varied substantially (and often overlapped), but was always within $30 \mathrm{~m}$ of the starting point of transects 1 and 2

responsible for measuring habitat features. The fish count diver only counted fish greater than $15 \mathrm{~cm}$ TL that occurred within $5 \mathrm{~m}$ of the transect line. The UVC response variable was the number of individuals seen per transect (i.e. individuals per $300 \mathrm{~m}^{2}$ ). When large numbers of fish were present, the fish diver visually estimated the total abundance for each species. The fish diver also estimated the lengths of all fish seen in each transect into TL bins (e.g. 15-19, 20-29, 30-39 cm, and so on). The habitat diver trailed the fish diver and quantified habitat within 3 blocks $(10 \mathrm{~m} \times 10 \mathrm{~m})$, centered on 5,15 , and $25 \mathrm{~m}$ along each transect line (Fig. 3). Within each of the 9 blocks ( 3 blocks per transect $\times 3$ transects) at a site, the same 2 habitat variables were estimated as they were from video. For each habitat variable, the mean of the 9 values (for each $10 \mathrm{~m} \times 10 \mathrm{~m}$ square) was used as the UVC estimate for that site.

\section{Data analyses}

We first provided gear-specific counts or catches for all taxa in our study, but all subsequent analyses focused only on those species that were seen or caught in sufficient numbers (i.e. present in $>5 \%$ of samples) in all gears. Five species met these criteria: tomtate Haemulon aurolineatum, vermilion snapper Rhomboplites aurorubens, black sea bass, red snapper, and gray triggerfish Balistes capriscus. Two additional species - lionfish Pterois spp. and gray snapper Lutjanus griseus - met the minimum threshold for UVC and video but were not caught in traps, so they were included in comparisons between UVC and video gears but excluded from all trap analyses. These 7 species are hereafter referred to as the 'focal' species of this study.

We first determined the percent frequency of occurrence of each of the 7 focal species for each of the 3 sampling gears used in this study, which provides information about which gears were more or less likely to detect each of the focal species. Percent frequency of occurrence was calculated as the proportion of sites in which the species was caught or observed, multiplied by 100 . We next calculated mean UVC densities, video counts, and trap catch for each of the focal species. There were various ways we could calculate fish density from UVC, so we calculated UVC densities in 5 separate ways and compared each of these to site-specific video counts and trap catches. These were: density of fish from the first transect, density of fish from the second transect, density of fish from the third transect, the mean density of fish from all 3 transects, and the density of fish for whichever of the 3 transects had the highest (maximum) density. Comparisons of fish densities from UVC helped us to choose which density calculation was the most strongly related to video counts or trap catch.

Next we calculated the focal-species-specific correlations for each unique gear combination (i.e. UVC $\times$ video, UVC $\times$ trap, video $\times$ trap) to determine how well the catches or counts from the gears were correlated with each other. We used the Spearman's rank correlation coefficient $(\rho)$, a non-parametric test that quantifies the strength of correlation between 2 vari- 
ables without needing to assume normality. We developed a table showing $\rho$-values for mean video counts and trap catches for each of the 5 UVC transect configurations described above.

We next compared the lengths of focal species estimated by UVC to those caught by traps. There are 2 primary mechanisms that might explain differences in lengths between these 2 sampling techniques: differences in the selectivity between traps and UVC, as well as biased lengths from UVC due to errors in visual estimation. It is impossible to completely disentangle these 2 processes with our dataset because we do not know what the true size distribution for each species was, but length comparisons between gears may be informative and could guide the design of future studies.

We next compared the site-specific number of species observed among the 3 gears using Spearman's rank correlation coefficient. When taxa could not be identified to the species level by UVC or video, they were not included in the calculation of the total number of species for each gear unless no other taxa in that same genus was also present in that gear's count.

Last, we compared ( $\rho$ ) the percent hard bottom and percent biotic coverage estimated from video to estimates from UVC. The primary goal of this analysis was to determine if the habitat recorded on underwater video cameras at a relatively small scale was similar to the habitat recorded by UVC that was integrated over a larger $\left(900 \mathrm{~m}^{2}\right)$ area. Note that the spatial footprint of habitat observed on video was not necessarily a subset of the habitat observed by UVC, and in some cases there was no overlap at all between the 2 gears (see Fig. 3).

\section{RESULTS}

Overall, 117 taxa were observed from simultaneous UVC, video, and trap sampling at 77 stations in the SEUS (Table S1 in the Supplement at www. int-res.com/articles/suppl/m574p141_supp.pdf). A total of 100 taxa were observed during UVC, which included 94 species, 1 hybrid species (Holacanthus ciliaris $\times H$. bermudensis), and 5 taxa that were identified to genus (Calamus, Carcharhinus, Decapterus, Paralichthys, and Pterois). Thirty-five taxa observed by UVC were not observed on videos or caught in traps. A total of 82 taxa were observed on video, including 75 species, 1 hybrid species (H. ciliaris $\times H$. bermudensis), and 6 taxa that were identified to genus (Calamus, Decapterus, Ogcocephalus, Paralichthys, Pterois, and Stenotomus). Seventeen spe- cies observed on video were not observed by UVC or caught in traps. Chevron traps caught a total of 20 taxa (Table S1), all of which were also recorded by $\mathrm{UVC}$ and video.

Tomtate was the most abundant species from UVC (112 fish per $300 \mathrm{~m}^{2}$ ), videos (838 SumCount per site), and traps (41 fish per trap). The second (Decapterus spp.), third (vermilion snapper), and fourth (black sea bass) most abundant species were the same from UVC and videos, whereas Decapterus spp. was not caught in traps and black sea bass was the second most abundant species in traps. A total of 14 species were observed by UVC with a density $>1$ individual per $300 \mathrm{~m}^{2}$, and a total of 21 species were observed on videos with a mean SumCount $>1$. Three species had a mean trap catch $>1$ fish per trap.

The rank abundance of species observed by UVC and on video was broadly similar, but there were many exceptions. For instance, UVC tended to document higher rank abundances of some small (painted wrasse Halichoeres caudalis, wrasse basslet Liopropoma eukrines), secretive (cubbyu Pareques umbrosus, squirrelfish Holocentrus adscensionis, whitespotted soapfish Rypticus maculatus), camouflaged (lionfish Pterois spp., spotted scorpionfish Scorpaena plumieri, oyster toadfish Opsanus tau), and schooling pelagic (blue runner Caranx crysos, Atlantic bumper Chloroscombrus chrysurus, little tunny Euthynnus alletteratus) species compared to video (Table S1). Alternatively, video tended to document higher rank abundances of species that are attracted to bait (e.g. red snapper Lutjanus campechanus, gray triggerfish Balistes capriscus, sand perch Diplectrum formosum, pinfish Lagodon rhomboides, various shark species) and those that might avoid divers (unicorn filefish Aluterus monocerus, Stenotomus spp.). Similar to video, traps were represented primarily by species that are attracted to bait, albeit many fewer species in total.

Tomtate had the highest percent frequency of occurrence of any focal species in each of the 3 sampling gears used in our study ( $86 \%$; Table 1$)$. Black sea bass and lionfish were the second-most frequently observed focal species by UVC (70\%), followed by vermilion snapper and gray triggerfish (64\%), gray snapper $(57 \%)$, and red snapper $(30 \%)$. In contrast, video documented vermilion snapper the second-most frequently $(73 \%)$, followed by black sea bass $(57 \%)$, gray triggerfish (55\%), red snapper (38\%), gray snapper $(34 \%)$, and lionfish $(13 \%)$. Traps commonly caught black sea bass $(69 \%)$, and less frequently caught gray triggerfish $(30 \%)$, vermilion snapper $(25 \%)$, and red snapper (18\%), and did not catch gray 
Table 1. Percent of samples from underwater visual census (UVC), videos, and traps where each reef fish species was present (i.e. seen or caught) during multigear sampling on the east coast of Florida, USA, 2014

\begin{tabular}{|llccc|}
\hline Species & & UVC & Video & Trap \\
\hline Tomtate & Haemulon aurolineatum & 86 & 86 & 86 \\
Vermilion snapper & Rhomboplites aurorubens & 64 & 73 & 25 \\
Black sea bass & Centropristis striata & 70 & 57 & 69 \\
Red snapper & Lutjanus campechanus & 30 & 38 & 18 \\
Gray triggerfish & Balistes capriscus & 64 & 55 & 30 \\
Gray snapper & Lutjanus griseus & 57 & 34 & 0 \\
Lionfish & Pterois spp. & 70 & 13 & 0 \\
\hline
\end{tabular}

Table 2. Mean density, counts, or catch of 7 focal reef fish species during multigear sampling in Florida, 2014. Mean densities of fish from underwater visual census (UVC) transects were measured as the number of fish per $300 \mathrm{~m}^{2}$, and are shown separately for the first, second, and third transects, as well as the maximum and the mean of all transects. For video, density was measured as the mean of all individuals of each species observed across each of the 41 frames of both videos, and for traps, it was the mean trap catch of each species

\begin{tabular}{|lcccccccc|}
\hline \multirow{2}{*}{ Species } & \multicolumn{9}{c}{ UVC transects } & \multirow{2}{*}{ Video } & \multirow{2}{*}{ Trap } \\
\cline { 2 - 6 } & 1 & 2 & 3 & Max & Mean & & \\
\hline Tomtate & 140.84 & 123.55 & 72.36 & 177.60 & 112.25 & 836.22 & 42.14 \\
Vermilion snapper & 21.97 & 20.74 & 8.81 & 30.04 & 17.17 & 111.61 & 0.74 \\
Black sea bass & 8.57 & 7.35 & 4.96 & 11.35 & 6.96 & 21.52 & 12.05 \\
Red snapper & 2.53 & 1.48 & 1.06 & 3.01 & 1.69 & 10.34 & 1.37 \\
Gray triggerfish & 1.26 & 1.55 & 0.34 & 2.26 & 1.05 & 8.08 & 0.64 \\
Gray snapper & 2.40 & 2.43 & 0.75 & 4.28 & 1.86 & 4.44 & 0.00 \\
Lionfish & 3.00 & 2.34 & 0.95 & 3.08 & 2.10 & 3.49 & 0.00 \\
\hline
\end{tabular}

Table 3. Spearman's rank correlation coefficients $(\rho)$ for underwater video or chevron traps and 5 combinations of underwater visual census (UVC) transect data during simultaneous multi-gear sampling in Florida, 2014. Shown are $\rho$ values for traps or videos related to each of the 3 separate UVC transects, the transect containing the maximum density in each UVC sample, and the mean density across all 3 transects for each of the focal reef fish species. Asterisks denote significance: ${ }^{*} \mathrm{p}<0.05 ;{ }^{* *} \mathrm{p}<0.01 i^{* * *} \mathrm{p}<0.001$

\begin{tabular}{|lccccl|}
\hline & \multicolumn{4}{c}{ Transect } & \multicolumn{2}{c|}{ Max } & Mean \\
\cline { 2 - 4 } & 1 & 2 & 3 & & \\
\hline Video & & & & & \\
Tomtate & $0.70^{* * *}$ & $0.48^{* * *}$ & $0.53^{* * *}$ & $0.70^{* * *}$ & $0.68^{* * *}$ \\
Vermilion snapper & $0.64^{* * *}$ & $0.53^{* * *}$ & $0.46^{* * *}$ & $0.68^{* * *}$ & $0.69^{* * *}$ \\
Black sea bass & $0.76^{* * *}$ & $0.68^{* * *}$ & $0.72^{* * *}$ & $0.79^{* * *}$ & $0.82^{* * *}$ \\
Red snapper & $0.56^{* * *}$ & $0.70^{* * *}$ & $0.53^{* * *}$ & $0.76^{* * *}$ & $0.76^{* * *}$ \\
Gray triggerfish & $0.56^{* * *}$ & $0.42^{* *}$ & $0.23^{*}$ & $0.53^{* * *}$ & $0.56^{* * *}$ \\
Gray snapper & $0.39^{* *}$ & $0.40^{* *}$ & $0.41^{* * *}$ & $0.44^{* * *}$ & $0.49^{* * *}$ \\
Lionfish & 0.08 & 0.17 & 0.03 & 0.13 & 0.17 \\
& & & & & \\
Trap & & & & & \\
Tomtate & $0.50^{* * *}$ & $0.42 \ldots$ & $0.43^{* *}$ & $0.53^{* * *}$ & $0.52^{* * *}$ \\
Vermilion snapper & $0.46^{* * *}$ & $0.31^{* *}$ & 0.20 & $0.31^{* *}$ & $0.34^{* *}$ \\
Black sea bass & $0.79^{* * *}$ & $0.68^{* * *}$ & $0.75^{* * *}$ & $0.84^{* * *}$ & $0.86^{* * *}$ \\
Red snapper & $0.52^{* * *}$ & $0.67^{* * *}$ & $0.47^{* * *}$ & $0.63^{* * *}$ & $0.64^{* * *}$ \\
Gray triggerfish & $0.38^{* * *}$ & 0.20 & 0.10 & $0.30^{* *}$ & $0.31^{* *}$ \\
\hline
\end{tabular}

snapper or lionfish $(0 \%)$. Generally, UVC was best at documenting gray triggerfish, gray snapper, and lionfish, while video was best at documenting vermilion snapper and red snapper (Table 1).

Mean abundance of focal species via UVC varied substantially by transect (Table 2). For 5 of 7 focal species, mean abundance declined from the first to the third transects surveyed by UVC, while the second transect had the highest mean abundance for the remaining 2 species, gray triggerfish and gray snapper. The third transect always had the lowest mean abundance of any transect, and, for 5 of 7 species, mean abundance was more than $50 \%$ lower than the first transect.

Mean abundance from all 3 UVC transects tended to be more highly correlated with video counts and trap catches than any of the UVC transects by themselves or the abundance from the maximum transect (Table 3). Six of the 7 focal species had higher correlations (based on $\rho$-values) between video counts and the mean abundance of all UVC transects compared to individual or maximum transects, as did the trap catches of 1 of the 5 focal species. Video counts had the lowest correlation with the third UVC transect for 4 of 7 focal species, and trap catches had the lowest correlation with the third UVC transect for 3 of 5 focal species (Table 3). Given that the overall mean abundance across all 3 transects was the best UVC density metric for the most focal species, it was used in all subsequent analyses.

Correlations in the catches or counts among the 3 sampling gears varied in our study. The highest correlations between video counts and mean UVC abundance (across all 3 transects) occurred for black sea bass $(\rho=0.82)$, followed by red snapper (0.76), vermilion snapper (0.69), tomtate (0.68), gray triggerfish (0.56), gray snapper (0.49), and lionfish $(0.17$; Table 3, Fig. 4). Similarly, the highest correlations between trap catch and mean UVC abundance occurred for black sea bass ( $\rho=$ 0.86), followed by red snapper (0.64), tomtate 

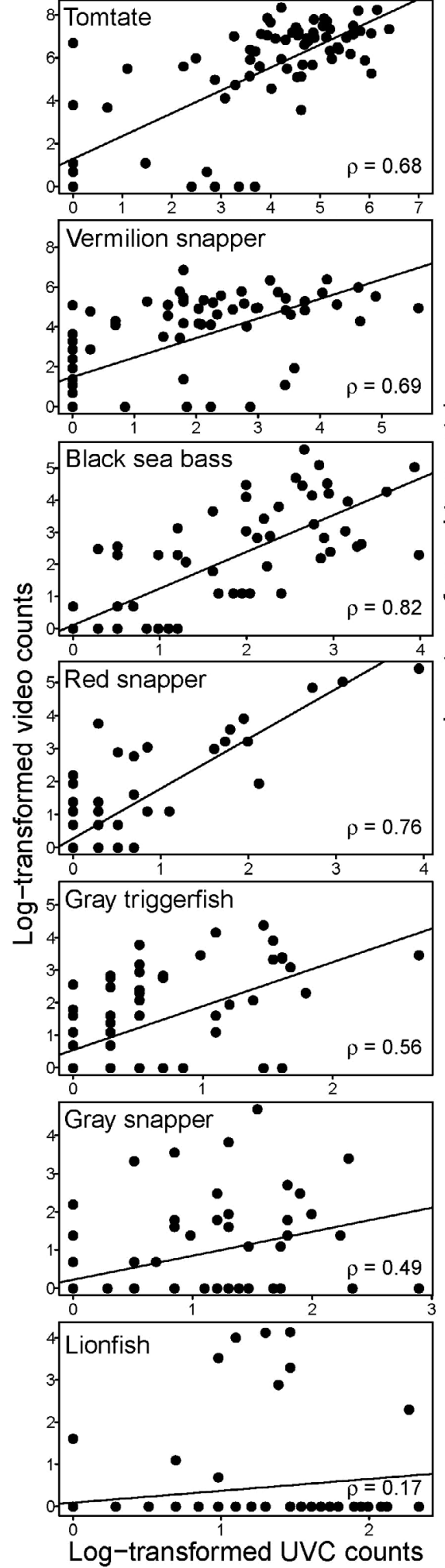
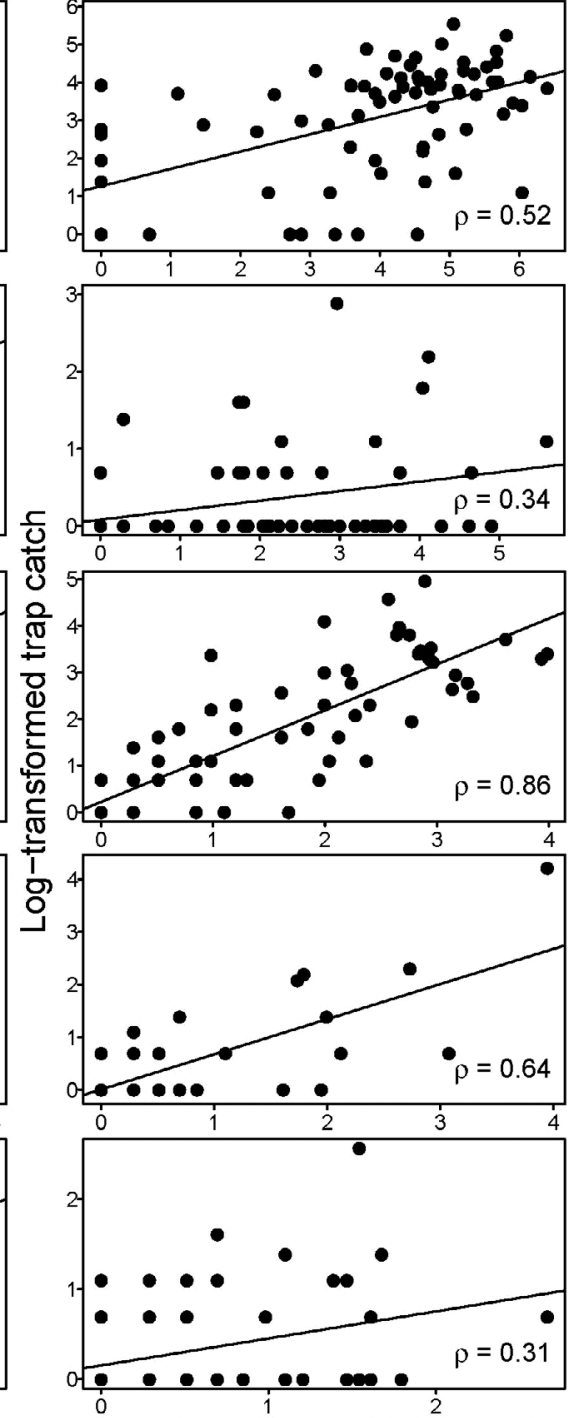

Log-transformed UVC counts
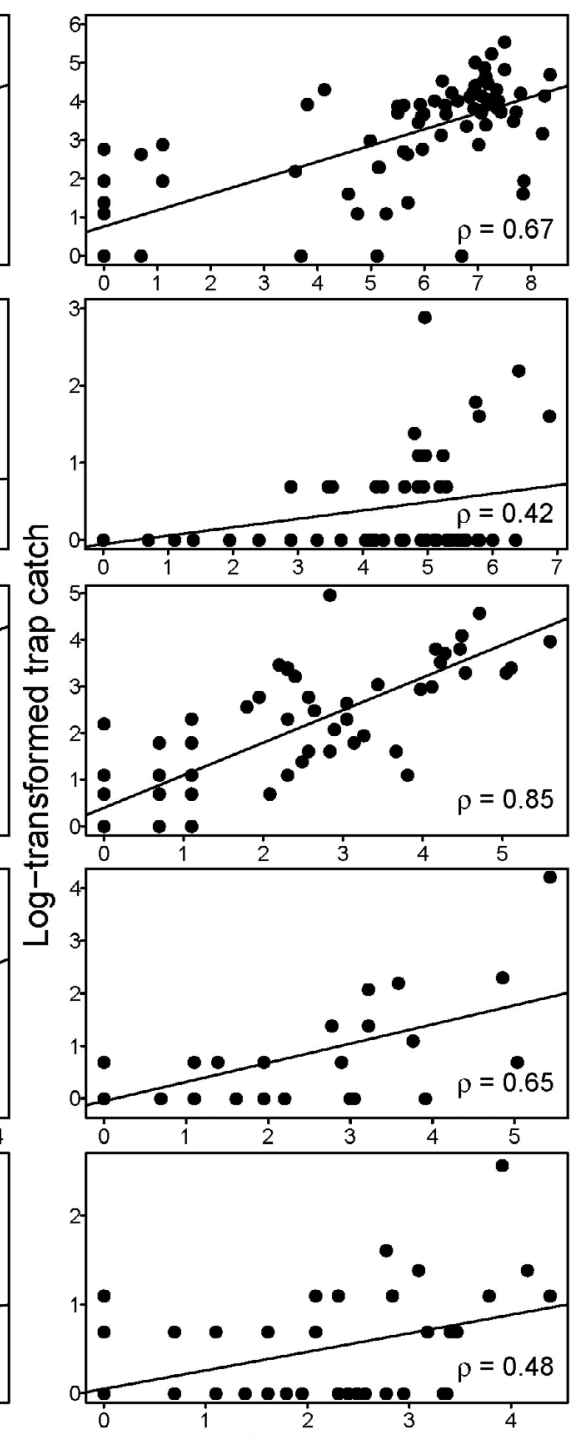

Log-transformed video counts

Fig. 4. Comparison of log-transformed video and underwater visual census (UVC) counts (left column), trap catch and UVC counts (middle column), and video counts and trap catch (right column) for various reef fish species (rows) during simultaneous sampling in Florida, 2014. Spearman's rank correlation coefficients ( $\rho)$ are shown in each panel for each comparison. Only species present in $>5 \%$ of samples in each of the gear comparisons are shown

(0.52), vermilion snapper (0.34), and gray triggerfish (0.31). Video counts were more highly correlated with mean UVC abundance than traps for all focal species except black sea bass, which were similarly related to UVC abundance ( $\rho=0.86$ for traps, 0.82 for video; Table 3). Correlations ( $\rho$ ) among video and 
UVC for the remaining species were higher compared to traps and UVC, ranging from 0.12 higher for red snapper to 0.35 higher for vermilion snapper (Table 3). Gray snapper and lionfish were not caught in traps and correlations were lower between videos and UVC for those 2 species compared to other focal species (Table 3, Fig. 4). There was a high correlation between video counts and trap catch for black sea bass (0.85), but correlations were lower for tomtate $(0.67)$, red snapper $(0.65)$, gray triggerfish $(0.48)$, and vermilion snapper (0.42; Fig. 4).
There were some differences in the lengthfrequency distributions for focal species estimated by UVC and caught in traps. For instance, individuals in the smallest length bins (10-19 cm TL) across all species were underrepresented in traps (Fig. 5). There were also a few instances where lengths of tomtate and gray triggerfish estimated by UVC were larger than any individuals of those species observed in traps, but maximum lengths for vermilion snapper, black sea bass, and red snapper were very similar between gears (Fig. 5).
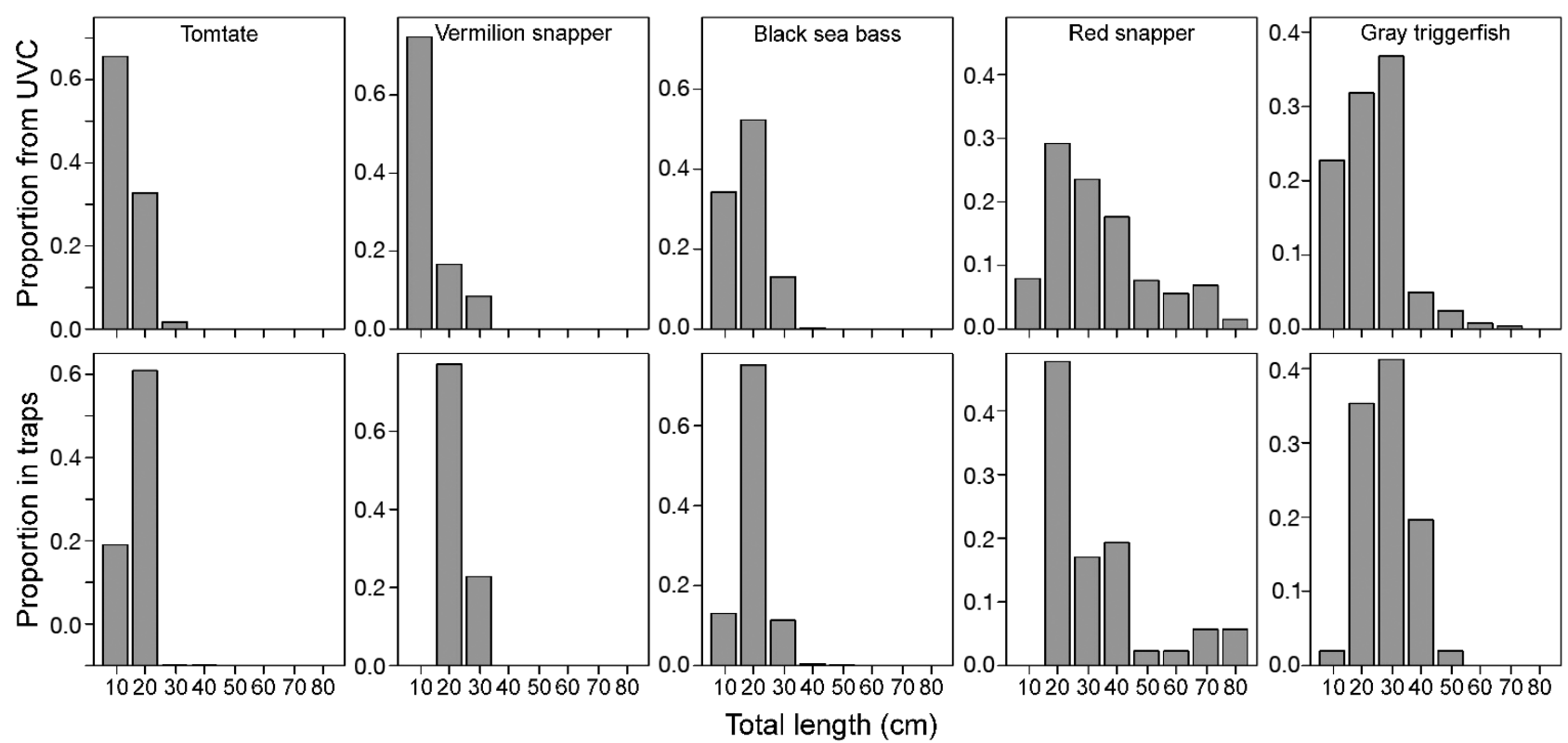

Fig. 5. Length comparisons for 5 reef fish species from underwater visual census (UVC; top row) and those caught in chevron fish traps (bottom row). Data are shown as a proportion of fish in each size bin to facilitate comparisons between gears. Category labels on the $x$-axes refer to the minimum size of fish in that category $(10: 10-19 \mathrm{~cm} ; 20: 20-29 \mathrm{~cm}$; etc.)
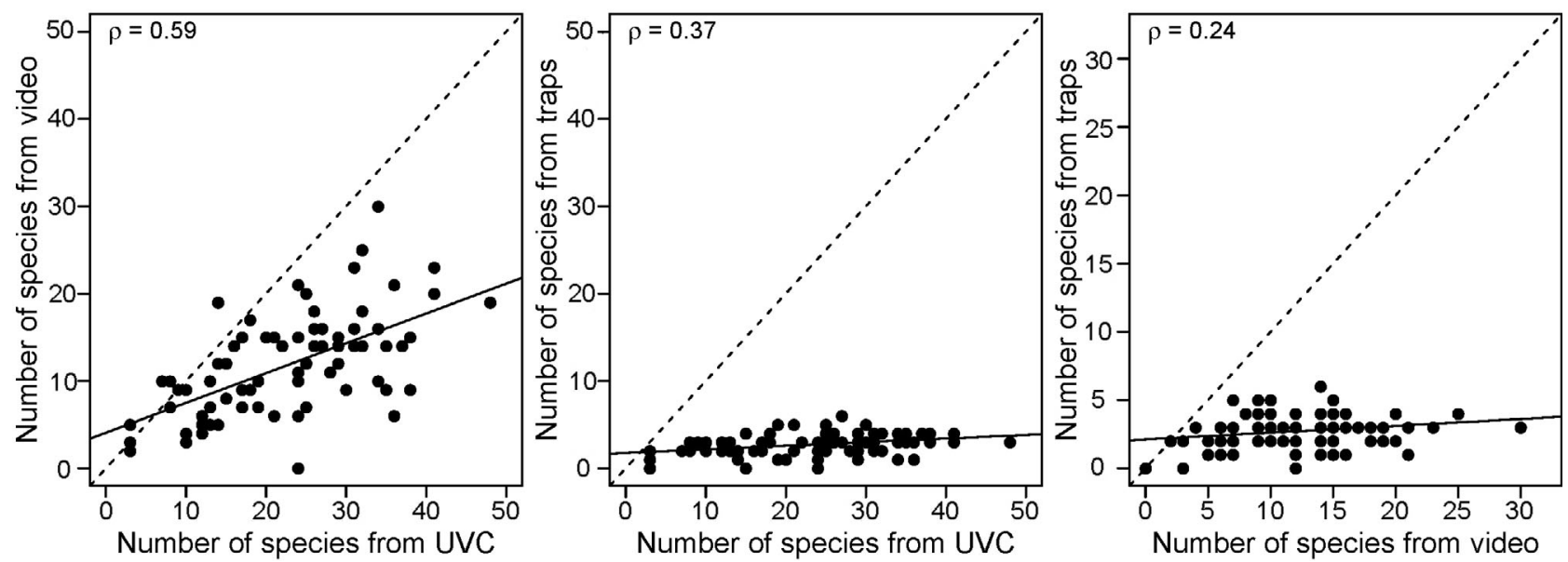

Fig. 6. Comparisons of the number of species seen at each site by underwater visual census (UVC), video, or traps in Florida, 2014. The number of species from UVC was the total number of species observed across the 3 dive transects at each site. Trend lines are indicated by the solid lines, dashed lines indicate a 1:1 relationship, and Spearman's rank correlation coefficients $(\rho)$ are shown in each panel 
The highest number of species per site was obtained via UVC (mean $=23$; range $=3-48$ ), followed by video $($ mean $=12$; range $=0-30)$ and traps (mean $=3$; range $=0-6$; Fig. 6). The number of species observed by UVC at each site was positively related to the number of species observed at each site by video $(\rho=0.59)$, but the relationship between UVC and traps was weaker ( $\rho=0.37$; Fig. 6$)$. The relationship between video and traps in terms of number of species encountered was especially weak ( $\rho=0.24)$.

Last, there were positive relationships between habitat variables quantified by UVC and those estimated from videos, despite the 2 gears quantifying habitat over differing spatial scales that often did not overlap (Fig. 7). The relationship between the esti-
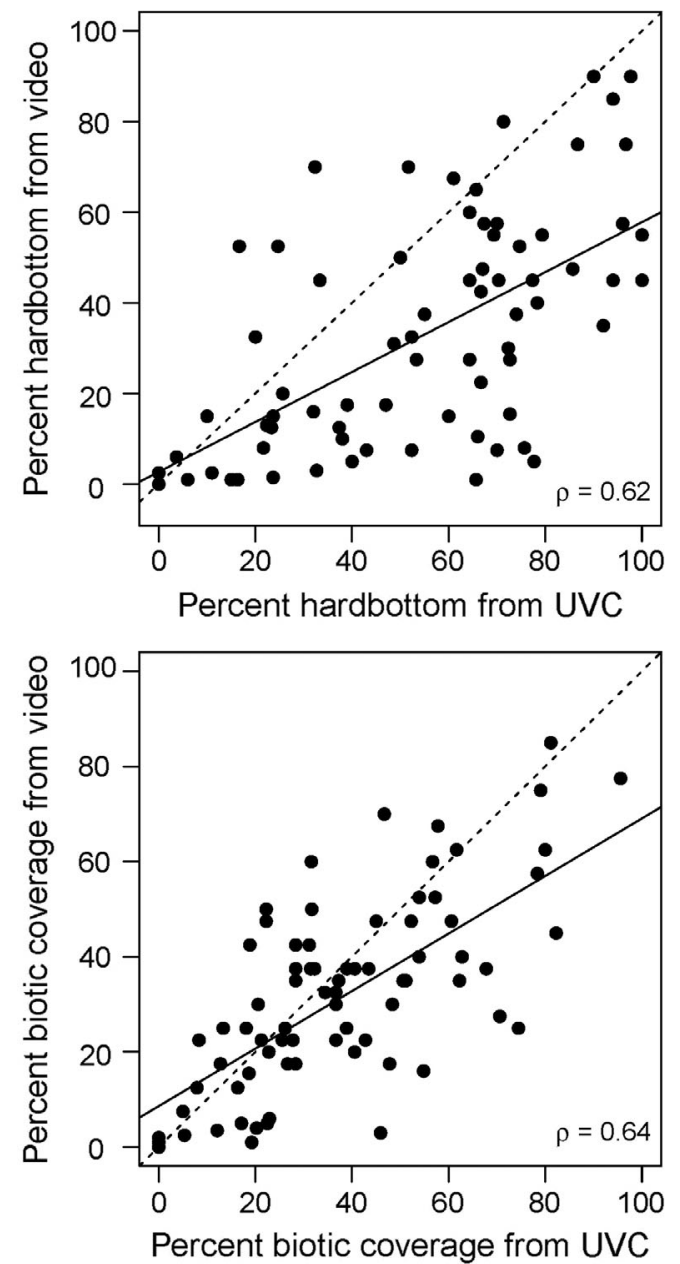

Fig. 7. Relationship between underwater visual census (UVC; mean of all 9 habitat samples per site) and underwater video in estimating the percent hardbottom habitat (top panel) and percent of the bottom with attached biota (bottom panel) in Florida, 2014. Trend lines are indicated by the solid lines, dashed lines indicate a 1:1 relationship, and Spearman's rank correlation coefficients $(\rho)$ are shown in each panel mated percent biotic coverage from videos compared to UVC ( $\rho=0.64$ ) was slightly higher than the relationship between the estimated percent hard bottom from videos and UVC ( $\rho=0.62$; Fig. 7).

\section{DISCUSSION}

All sampling gears select for certain species or sizes of individuals, which complicates scaling up catches or counts to true abundance unless we know the exact ways in which gears are biased. The best approach to understand the biases of sampling gears is to compare gear-specific catches or counts to known abundance, but a complete census of an area is often very difficult or impossible to obtain, especially for marine fish (Parker et al. 2016). Therefore, most previous work has compared catches or counts from multiple gears to make inferences about gearspecific biases, commonly deploying gears either sequentially or independently in space and time (e.g. Ellis \& DeMartini 1995, Willis et al. 2000, Harvey et al. 2012). While much has been learned about gear biases from this work, the highly patchy and variable distribution of fish in space and time has likely resulted in more variability between gears than would be expected if sampling occurred simultaneously (Karnauskas \& Babcock 2012, Mallet et al. 2014). To address this concern, we instead surveyed reef fish in the same area at the same time using UVC, video, and traps, and compared catches or counts, number of species, fish lengths, and habitat among gears to make inferences about the biases of each gear. These results help us to understand the strengths, weaknesses, and biases of UVC, video, and traps in our study area, allowing us to make inferences about how gear-specific catches or counts may be related to true abundance.

As hypothesized, species-specific catches or counts and the number of species observed were much more similar between UVC and video than either gear was with traps. Correlations among catches or counts for 6 out of 7 focal species were highest between UVC and video than any other gear combination, with black sea bass being the single exception. Black sea bass had the highest correlation for traps and video and are known to be highly attracted to baited fish traps (Bacheler et al. 2013c). All 3 gears appeared to index black sea bass abundance well, however, given that all gear combinations were highly correlated for black sea bass $(\rho \geq 0.82)$. The number of species caught or seen was also much higher for UVC (100) and video (82) compared to traps (20), which 
also translated into a higher site-specific correlation of number of species for UVC and video compared to any other gear combination. These results correspond well to previous studies showing that visual techniques tend to index the presence and abundance of most species better than traps (Cappo et al. 2003, Harvey et al. 2012, Bacheler et al. 2013a) or other baited gears (Willis et al. 2000, Parker et al. 2016). Although highly related, differences between video and UVC may be due to gear-specific selectivities and the different spatial footprint surveyed by each gear, which may have been larger for UVC compared to video (Fig. 3).

There was substantial species-specific variability in how well catches or counts were correlated among gears, which was likely related to fish behavior. The catches or counts of black sea bass, red snapper, and tomtate were highly correlated among all 3 sampling gears, likely because they are easily observed by UVC and highly attracted to bait (Patterson et al. 2012, Bacheler et al. 2013a). That the frequency of occurrence for red snapper was higher on video compared to UVC suggests a strong attraction to bait, even though they were caught in traps $<50 \%$ as often as seen on video (Bacheler et al. 2013a, Coggins et al. 2014). In contrast, the correlations for vermilion snapper, gray triggerfish, gray snapper, and lionfish were much weaker. Gray snapper and lionfish are wary and are rarely caught in traps (Bacheler et al. 2013a), and their lack of attraction to baited traps also likely minimized their observations on video cameras that were attached to baited traps in our study. The reasons for lower correlations among gears for vermilion snapper and gray triggerfish are unknown. Vermilion snapper are a schooling species, and their patchy distribution may have resulted in weak correlations among gears despite relatively high frequency of occurrence from UVC and video. The ability of traps and video to observe vermilion snapper and gray triggerfish is also influenced by environmental and habitat characteristics (Bacheler et al. 2014) and perhaps behavioral interactions in and around the trap (e.g. Jury et al. 2001), which may cause additional variability in the relationships between gears.

There were some differences in lengths of fish caught in traps compared to lengths of fish estimated by UVC. For all 5 focal species examined, a higher proportion of individuals in the smallest length bin $(10-19 \mathrm{~cm}$ TL) was observed by UVC than caught in traps, likely due to the ability of small fish to escape through the $3.4 \mathrm{~cm}$ mesh of the trap (Bohnsack et al. 1989, Rudershausen et al. 2008). There were also some tomtate and gray triggerfish observed by UVC that were bigger than those caught in traps, which could either be due to trap selection or errors in lengths estimated by UVC. The trap mouth opening in our study was large, allowing these traps to capture very large individuals of a variety of species (e.g. Mitchell et al. 2014). Moreover, Harvey et al. (2012) and Langlois et al. (2015) found that traps often caught the same size fish or slightly bigger than those observed using stereo-video, suggesting that traps do not exhibit reduced selectivity for larger fish within a reasonable range of fish sizes. The most plausible explanation, therefore, may be that lengths of these 2 species estimated by UVC lacked some amount of accuracy or precision, which has been found in previous studies (Bell et al. 1985, St. John et al. 1990, Harvey et al. 2002). This explanation seems especially likely for gray triggerfish given that the largest gray triggerfish observed by UVC in our study (70-79 cm TL) was larger than the largest gray triggerfish included in the recent SEUS assessment (i.e. $69 \mathrm{~cm} \mathrm{TL}$; SEDAR 2016).

In the ecological literature, it is common to make inferences about spatial or temporal patterns in biodiversity using the catches from traditional sampling gears, but our results suggest that gears may only sample a segment of the entire fish community. For instance, we showed that video observed $310 \%$ more species than traps and UVC observed $400 \%$ more species than traps. These results are similar to, but more extreme than, the results of Harvey et al. (2012). Video and UVC tended to observe a wide array of species at a site, encompassing all major functional groups, while traps almost exclusively caught various highly-mobile predator and scavenger species (Robichaud et al. 2000). Traps also did a poor job of tracking the number of species seen at each site by UVC $(\rho=0.37)$ or videos $(\rho=0.24)$. The differences in total species observed between UVC and video were much smaller, with UVC observing $21 \%$ more species than video $(\rho=0.59$ between gears). Divers were able to observe fish under ledges and in crevices, thus doing a better job of observing small, secretive, and camouflaged species that were often missed on video (Mallet et al. 2014). However, UVC also missed a significant number of species $(\mathrm{N}=$ 17) that were observed on video, suggesting that none of the gears used in our study perfectly sampled the reef fish community in the SEUS.

Habitat observed on video was positively correlated with habitat observed by UVC, but there was a significant amount of unexplained variability in each correlation. Two widely used habitat variables were 
scored by video and UVC in our study: percent hard bottom and percent biotic coverage (e.g. Bacheler et al. 2014). We expect that the correlation of habitat variables among these 2 gears would have been higher had they sampled the same spatial footprint. Instead, UVC quantified habitat over a large area of $900 \mathrm{~m}^{2}$, while habitat on video was scored over a smaller area. Moreover, the area scored for habitat on video may or may not have been encompassed in the area scored for habitat by UVC. These results suggest that video-based habitat quantification can approximate the habitat observed by UVC over a larger spatial scale, perhaps due to the correlation of reef habitats across space (Saul et al. 2013).

The benefits of using UVC to collect populationand community-level fish data have been well known since the 1970s (Connell et al. 1998), but there are some drawbacks to the approach. In our study, UVC covered a larger area than video sampling and recorded the highest number (and most diverse composition) of species, suggesting it may be the best gear for collecting community-level information, but UVC is costly in terms of personnel time required for surveys. Additionally, UVC is limited to safe diving depths, and fish may avoid or be attracted to divers, making the calculation of absolute densities challenging. For instance, Willis et al. (2000) showed that UVC provided the least reliable measure of snapper density in New Zealand because snapper quickly fled divers. Although not quantified in our study, video readers did note that black sea bass and tomtate commonly followed divers observed on video, while most other species seemed to flee from them; only counting fish in front of divers likely helped to alleviate this problem. We also observed variability in fish counts across the 3 transects surveyed, which might be explained by habitat differences among the 3 transects, or perhaps a flight response from, or attraction to, divers by various fish species. Larger fish have also been shown to have a stronger flight response from divers compared to smaller fish (Bozec et al. 2011), suggesting that detectability of fish by UVC might be size-dependent. In addition, UVC missed 3 species of sharks that were observed on video, suggesting that UVC may disproportionally miss highly mobile species (Mallet et al. 2014), especially those attracted to bait.

Underwater video has also been a common approach to index the abundance and describe the behavior of various species around the world (Mallet \& Pelletier 2014, Aguzzi et al. 2015). Video is often used in places where depth, bottom structure, or fish behavior limit sampling with other sampling gears, and like UVC, is a non-extractive sampling gear, which can be particularly useful in no-take reserves (Murphy \& Jenkins 2010). Video can also be used to estimate fish length with high accuracy and precision using stereo-video cameras (Harvey et al. 2002). Videos can be stored to provide a record of a sample or site for many years, and can be baited or not, depending on the specific objectives of the study (Dorman et al. 2012). Video does have shortcomings, including the expense of purchasing video cameras and reading the subsequent videos, effects of water clarity and current on video detectability (Bacheler et al. 2014), and its inability to extract fish for biological samples when needed. Also, fish must be counted on videos using a standardized methodology proportional to their true abundance (Schobernd et al. 2014).

Traps can be used very successfully as long as their shortcomings are known and accounted for. Fish traps have been used to index the abundance of reef-associated fish species around the world, including the Caribbean (Recksiek et al. 1991), Bermuda (Evans \& Evans 1996), Mediterranean Sea (Jones et al. 2003), Gulf of Mexico (Wells et al. 2008), and the SEUS (Rudershausen et al. 2010, Bacheler \& Smart 2016). For instance, traps catch some species in proportion to their site abundance (Bacheler et al. 2013c, Shertzer et al. 2016), and, as we found in this study, some species may be caught in traps more commonly than seen on video (Wells et al. 2008, Bacheler et al. 2013a). Another benefit of traps is that it is much easier to identify taxa to the species level than by video or UVC, because the individual has been captured. Last, it is often advantageous to collect biological samples from fish, such as tissue samples for genetic analysis, reproductive tissue for assessment of population sex ratios and timing of reproduction, and otoliths, scales, or spines for age-based management of fishery resources. As we showed in our study, however, the downsides of traps are substantial. Relatively few species were captured in traps compared to those observed by video or UVC, and those that were captured tended to be weakly related to counts from UVC or video, despite simultaneous sampling of all 3 gears. Thus, traps should only be considered as a survey gear to assess the relative abundance of a subset of the fish community (e.g. highly-mobile predators and scavengers), and not to make inferences about the entire fish community (Harvey et al. 2012).

Although simultaneous sampling of gears in our experimental setup was required in order to reduce the influence of spatial and temporal variability in reef fish abundance, the results of our study should be extrapolated with some caution due to the poten- 
tial lack of independence between gears. The 2 most likely violations of independence between gears in our study were traps catching fish that were then unable to be observed by video or UVC, and divers influencing the counts of fish on video and catch of fish in traps. We consider the first potential violation of independence to have a negligible influence in our study. Fish counting by divers and video both occurred within the first $30 \mathrm{~min}$ of the trap deployment, so very little time had elapsed for the trap to catch fish before UVC and video counts had concluded. Moreover, traps often catch a relatively small portion of the fish available at a given site (i.e. low catchability), even for fish commonly caught in traps like black sea bass (Bacheler et al. 2013c) or red snapper (Coggins et al. 2014), so we expect UVC and video counts to be influenced negligibly by trap catch.

The second potential violation, whereby the presence of divers might influence video counts or trap catch, is more challenging to assess. As stated above, the presence of divers appeared to attract some fish and caused others to flee, and that may have caused some additional variability in video counts among the 41 frames read that was species-specific. The presence of divers likely influenced trap catches negatively, because fish would presumably be less likely to enter traps whether they were attracted to, or fleeing from, divers. However, divers were only present around traps during the first 30 min of the trap deployment, so all traps still had 21 to 69 min of uninterrupted time to catch fish. Moreover, traps in our study had very similar catches (i.e. total individuals and species) to the same traps deployed by the Southeast Reef Fish Survey in the region (Bacheler et al. 2013b), suggesting that if divers negatively influenced trap catch in our study, it was likely not a large source of bias.

We used simultaneous multi-gear sampling in the SEUS to better understand the relative strengths and weaknesses of UVC, video, and trap sampling for indexing reef fish abundance in the region. We showed that each gear missed species that were present, so none of these gears should be used to provide a complete, unbiased census of reef fish abundance and biodiversity. UVC may have been the least biased sampling approach, but still missed $21 \%$ of the species seen on video, similar to the results of Karnauskas \& Babcock (2012) and Mallet et al. (2014). Video recorded nearly as many species as UVC, but missed $35 \%$ of the species observed by UVC, mostly small, cryptic, and shy species (Mallet et al. 2014). Traps recorded just a fraction of species of UVC and video, suggesting it is the least efficient sampling gear. It should be noted that traps appeared to catch black sea bass, red snapper, and tomtate proportionally to video and UVC, so trap bias appears to be species-specific and not universal. Thus, the ideal gear to use in future studies depends on the objectives of the study, including the species of interest and logistical issues such as water depth, current speed, and water clarity. Given that each gear missed species and relative abundance measures were not perfectly correlated, each gear contains information that the others gears do not. Thus, information from multiple sampling gears may be leveraged in occupancy models (MacKenzie et al. 2002, Coggins et al. 2014) or N-mixture models (Royle 2004) that explicitly model and estimate detection or catchability rates.

Acknowledgements. We thank D. Grenda, J. Hackney, M. Judge, D. Meyer, and B. Teer for field assistance, the captain and crew of the M/V 'Spree', and acknowledge reviews of previous versions of this manuscript by A. Chester, A. Hohn, M. Karnauskas, and K. Shertzer. Funding was provided by the Marine Fisheries Initiative (in-house grant 13MFIH0006). Mention of trade names or commercial companies is for identification purposes only and does not imply endorsement by the National Marine Fisheries Service, NOAA.

\section{LITERATURE CITED}

Aguzzi J, Doya C, Tecchio S, De Leo FC and others (2015) Coastal observatories for monitoring of fish behavior and their responses to environmental changes. Rev Fish Biol Fish 25:463-483

Bacheler NM, Carmichael JT (2014) Southeast Reef Fish Survey video index development workshop. Final report. National Marine Fisheries Service and South Atlantic Fishery Management Council, Charleston, SC

* Bacheler NM, Shertzer KW (2015) Estimating relative abundance and species richness from video surveys of reef fishes. Fish Bull 113:15-26

Bacheler NM, Smart TI (2016) Multi-decadal decline in reef fish abundance and species richness in the southeast USA assessed by standardized trap catches. Mar Biol 163:26

* Bacheler NM, Schobernd CM, Schobernd ZH, Mitchell WA, Berrane DJ, Kellison GT, Reichert MJM (2013a) Comparison of trap and underwater video gears for indexing reef fish presence and abundance in the southeast United States. Fish Res 143:81-88

* Bacheler NM, Bartolino V, Reichert MJM (2013b) Influence of soak time and fish accumulation on catches of reef fishes in a multispecies trap survey. Fish Bull 111: 218-232

* Bacheler NM, Schobernd ZH, Berrane DJ, Schobernd CM, Mitchell WA, Geraldi NR (2013c) When a trap is not a trap: converging entry and exit rates and their effect on trap saturation of black sea bass (Centropristis striata). ICES J Mar Sci 70:873-882

Bacheler NM, Berrane DJ, Mitchell WA, Schobernd CM, Schobernd ZH, Teer BZ, Ballenger JC (2014) Environ- 
mental conditions and habitat characteristics influence trap and video detection probabilities for reef fish species. Mar Ecol Prog Ser 517:1-14

Bell JD, Craik GJS, Pollard DA, Russell BC (1985) Estimating length frequency distributions of large reef fish underwater. Coral Reefs 4:41-44

Bohnsack JA, Sutherland DL, Harper DE, McClellan DB, Hulsbeck MW, Holt CM (1989) The effects of fish trap mesh size on reef fish catch off southeastern Florida. Mar Fish Rev 51:36-46

Bozec YM, Kulbicki M, Laloë F, Mou-Tham G, Gascuel D (2011) Factors affecting the detection distances of reef fish: implications for visual counts. Mar Biol 158:969-981

Cappo M, Harvey E, Malcolm H, Speare P (2003) Potential of video techniques to monitor diversity, abundance and size of fish in studies of Marine Protected Areas. In: Beumer JP, Grant A, Smith DC (eds) Aquatic protected areas - What works best and how do we know? Proc World Congress on Aquatic Protected Areas. Australian Society for Fish Biology, Cairns, QLD, p 455-464

Cappo M, Speare P, De'ath G (2004) Comparison of baited remote underwater video stations (BRUVS) and prawn (shrimp) trawls for assessments of fish biodiversity in inter-reefal areas of the Great Barrier Reef Marine Park. J Exp Mar Biol Ecol 302:123-152

Coggins LG Jr, Bacheler NM, Gwinn DC (2014) Occupancy models for monitoring marine fish: a Bayesian hierarchical approach to model imperfect detection with a novel gear combination. PLOS ONE 9:e108302

Collen B, Pettorelli N, Baillie JEM, Durant SM (2013) Biodiversity monitoring and conservation: bridging the gaps between global commitment and local action. WileyBlackwell, London

Collins MR (1990) A comparison of three fish trap designs. Fish Res 9:325-332

Connell SD, Samoilys MA, Lincoln Smith MP, Leqata J (1998) Comparisons of abundance of coral-reef fish: catch and effort surveys vs visual census. Aust J Ecol 23: 579-586

* Dorman SR, Harvey ES, Newman SJ (2012) Bait effects in sampling coral reef fish assemblages with stereoBRUVS. PLOS ONE 7:e41538

Ellis DM, DeMartini EE (1995) Evaluation of a video camera technique for indexing abundances of juvenile pink snapper, Pristipomoides filamentosus, and other Hawaiian insular shelf fishes. Fish Bull 93:67-77

Elphick CS (2008) How you count counts: the importance of methods research in applied ecology. J Appl Ecol 45: 1313-1320

* Evans CR, Evans AJ (1996) A practical field technique for the assessment of spiny lobster resources of tropical islands. Fish Res 26:149-169

Harley SJ, Myers RA, Dunn A (2001) Is catch-per-unit-effort proportional to abundance? Can J Fish Aquat Sci 58: 1760-1772

Harvey ES, Fletcher D, Shortis M (2002) Estimation of reef fish length by divers and by stereo-video-a first comparison of the accuracy and precision in the field on living fish under operational conditions. Fish Res 57: 255-265

Harvey ES, Newman SJ, McLean DL, Cappo M, Meeuwig JJ, Skepper CL (2012) Comparison of the relative efficiencies of stereo-BRUVs and traps for sampling tropical continental shelf demersal fishes. Fish Res 125/126: 108-120
Jones EG, Tselepides A, Bagley PM, Collins MA, Priede IG (2003) Bathymetric distribution of some benthic and benthopelagic species attracted to baited cameras and traps in the deep eastern Mediterranean. Mar Ecol Prog Ser 251:75-86

Jury SH, Howell H, O'Grady DF, Watson WH III (2001) Lobster trap video: in situ video surveillance of the behaviour of Homarus americanus in and around traps. Mar Freshw Res 52:1125-1132

Karnauskas M, Babcock EA (2012) Comparisons between abundance estimates from underwater visual census and catch-per-unit-effort in a patch reef system. Mar Ecol Prog Ser 468:217-230

Klibansky N, Shertzer KW, Kellison GT, Bacheler NM (in press) Can subsets of species indicate overall patterns in biodiversity? Ecosphere

*LLanglois TJ, Harvey ES, Fitzpatrick B, Meeuwig JJ, Shedrawi G, Watson DL (2010) Cost-efficient sampling of fish assemblages: comparison of baited video stations and diver video transects. Aquat Biol 9:155-168

* Langlois TJ, Fitzpatrick BR, Fairclough DV, Wakefield CB and others (2012) Similarities between line fishing and baited stereo-video estimations of length-frequency: novel application of kernel density estimates. PLOS ONE 7:e45973

Langlois TJ, Newman SJ, Cappo M, Harvey ES, Rome BM, Skepper CL, Wakefield CB (2015) Length selectivity of commercial fish traps assessed from in situ comparison with stereo-video: Is there evidence of sampling bias? Fish Res 161:145-155

MacKenzie DI, Nichols JD, Lachman GB, Droege S, Royle JA, Langtimm CA (2002) Estimating site occupancy rates when detection probabilities are less than one. Ecology 83:2248-2255

MacNeil MA, Graham NAJ, Conroy MJ, Fonnesbeck CJ and others (2008) Detection heterogeneity in underwater visual-census data. J Fish Biol 73:1748-1763

*Mallet D, Pelletier D (2014) Underwater video techniques for observing coastal marine biodiversity: a review of sixty years of publications (1952-2012). Fish Res 154: $44-62$

*Mallet D, Wantiez L, Lemouellic S, Vigliola L, Pelletier D (2014) Complementarity of rotating video and underwater visual census for assessing species richness, frequency and density of reef fish on coral reef slopes. PLOS ONE 9:e84344

Maunder MN, Punt AE (2004) Standardizing catch and effort data: a review of recent approaches. Fish Res 70:141-159

Miller RJ (1990) Effectiveness of crab and lobster traps. Can J Fish Aquat Sci 47:1228-1251

*Mitchell WA, Kellison GT, Bacheler NM, Potts JC, Schobernd CM, Hale LF (2014) Depth-related distribution of postjuvenile red snapper in southeastern U.S. Atlantic Ocean waters: ontogenetic patterns and implications for management. Mar Coast Fish 6:142-155

Monk J (2014) How long should we ignore imperfect detection of species in the marine environment when modeling their distribution? Fish Fish 15:352-358

*Murphy HM, Jenkins GP (2010) Observational methods used in marine spatial monitoring of fishes and associated habitats: a review. Mar Freshw Res 61:236-252

Parker D, Winker H, Bernard ATF, Heyns-Veale ER, Langlois TJ, Harvey ES, Götz A (2016) Insights from baited video sampling of temperate reef fishes: How biased are angling surveys? Fish Res 179:191-201 
Patterson WF III, Porch CE, Tarnecki JH, Strelcheck AJ (2012) Effect of circle hook size on reef fish catch rates, species composition, and selectivity in the northern Gulf of Mexico recreational fishery. Bull Mar Sci 88:647-665

Recksiek CW, Appeldoorn RS, Turingan RG (1991) Studies of fish traps as stock assessment devices on a shallow reef in southwestern Puerto Rico. Fish Res 10:177-197

Richards LJ, Schnute JT (1986) An experimental and statistical approach to the question: Is CPUE an index of abundance? Can J Fish Aquat Sci 43:1214-1227

Robichaud D, Hunte W, Chapman M (2000) Factors affecting the catchability of reef fishes in Antillean fish traps. Bull Mar Sci 67:831-844

Royle JA (2004) $N$-mixture models for estimating population size from spatially replicated counts. Biometrics 60: 108-115

Rudershausen PJ, Baker MS Jr, Buckel JA (2008) Catch rates and selectivity among three trap types in the U.S. South Atlantic black sea bass commercial trap fishery. N Am J Fish Manag 28:1099-1107

Rudershausen PJ, Mitchell WA, Buckel JA, Williams EH, Hazen E (2010) Developing a two-step fishery-independent design to estimate the relative abundance of deepwater reef fish: application to a marine protected area off the southeastern United States coast. Fish Res 105: 254-260

Saul SE, Walter JF III, Die DJ, Naar DF, Donahue BT (2013) Modeling the spatial distribution of commercially important reef fishes on the West Florida shelf. Fish Res 143: $12-20$

Schobernd ZH, Bacheler NM, Conn PB (2014) Examining

Editorial responsibility: Ivan Nagelkerken,

Adelaide, South Australia, Australia the utility of alternative video monitoring metrics for indexing reef fish abundance. Can J Fish Aquat Sci 71: 464-471

SEDAR (Southeast Data Assessment and Review) (2016) SEDAR 41 - South Atlantic gray triggerfish assessment report. SEDAR, North Charleston, SC. http://sedarweb. org/sedar-41

Shertzer KW, Bacheler NM, Coggins LG Jr, Fieberg J (2016) Relating trap capture to abundance: a hierarchical statespace model applied to black sea bass (Centropristis striata). ICES J Mar Sci 73:512-519

* St. John J, Russ GR, Gladstone W (1990) Accuracy and bias of visual estimates of numbers, size structure and biomass of coral reef fish. Mar Ecol Prog Ser 64:253-262

*Wells RJD, Boswell KM, Cowan JH Jr, Patterson WF III (2008) Size selectivity of sampling gears targeting red snapper in the northern Gulf of Mexico. Fish Res 89: 294-299

Williams BK, Nichols JD, Conroy MJ (2002) Analysis and management of animal populations: modeling, estimation, and decision making. Academic Press, San Diego, CA

Willis TJ, Millar RB, Babcock RC (2000) Detection of spatial variability in relative density of fishes: comparison of visual census, angling, and baited underwater video. Mar Ecol Prog Ser 198:249-260

*Yoccoz N, Nichols J, Boulinier T (2001) Monitoring of biological diversity in space and time. Trends Ecol Evol 16: 446-453

Zuur AF, Ieno EN, Smith GM (2007) Analysing ecological data. Springer, New York, NY

Submitted: November 1, 2016; Accepted: April 25, 2017 Proofs received from author(s): June 16, 2017 